\title{
Corrosion and Corrosion Inhibition of High Strength Low Alloy Steel in 2.0 M Sulfuric Acid Solutions by 3-Amino-1,2,3-triazole as a Corrosion Inhibitor
}

\author{
El-Sayed M. Sherif, ${ }^{1,2}$ Adel Taha Abbas, ${ }^{1}$ D. Gopi, ${ }^{3,4}$ and A. M. El-Shamy ${ }^{2}$ \\ ${ }^{1}$ Mechanical Engineering Department, College of Engineering, King Saud University, P.O. Box 800, Riyadh 11421, Saudi Arabia \\ ${ }^{2}$ Electrochemistry and Corrosion Laboratory, Department of Physical Chemistry, National Research Centre (NRC), \\ Dokki, Cairo 12622, Egypt \\ ${ }^{3}$ Department of Chemistry, Periyar University, Salem 636 011, Tamil Nadu, India \\ ${ }^{4}$ Centre for Nanoscience and Nanotechnology, Periyar University, Salem 636 011, Tamil Nadu, India
}

Correspondence should be addressed to El-Sayed M. Sherif; esherif@ksu.edu.sa

Received 8 May 2014; Revised 8 August 2014; Accepted 1 September 2014; Published 11 September 2014

Academic Editor: Sylvain Franger

Copyright (c) 2014 El-Sayed M. Sherif et al. This is an open access article distributed under the Creative Commons Attribution License, which permits unrestricted use, distribution, and reproduction in any medium, provided the original work is properly cited.

The corrosion and corrosion inhibition of high strength low alloy (HSLA) steel after $10 \mathrm{~min}$ and $60 \mathrm{~min}$ immersion in $2.0 \mathrm{M}$ $\mathrm{H}_{2} \mathrm{SO}_{4}$ solution by 3-amino-1,2,4-triazole (ATA) were reported. Several electrochemical techniques along with scanning electron microscopy (SEM) and energy dispersive X-ray (EDS) were employed. Electrochemical impedance spectroscopy indicated that the increase of immersion time from $10 \mathrm{~min}$ to $60 \mathrm{~min}$ significantly decreased both the solution and polarization resistance for the steel in the sulfuric acid solution. The increase of immersion time increased the anodic, cathodic, and corrosion currents, while it decreased the polarization resistance as indicated by the potentiodynamic polarization measurements. The addition of $1.0 \mathrm{mM}$ ATA remarkably decreased the corrosion of the steel and this effect was found to increase with increasing its concentration to $5.0 \mathrm{mM}$. SEM and EDS investigations confirmed that the inhibition of the HSLA steel in the $2.0 \mathrm{M} \mathrm{H}_{2} \mathrm{SO}_{4}$ solutions is achieved via the adsorption of the ATA molecules onto the steel protecting its surface from being dissolved easily.

\section{Introduction}

High strength low alloy (HSLA) steels are designed to provide better mechanical properties and/or greater resistance to atmospheric corrosion than conventional carbon steels in the normal sense because they are designed to meet specific mechanical properties rather than a chemical composition [1]. HSLA steels have been widely used in many applications in industry; these include gun barrel, food sterilization, sintering of components from powders, hypersonic wind tunnels, power generation, and water jet cutting $[1,2]$. There is a great economical incentive in developing methods and materials to alleviate corrosion, which comes only from a good understanding of the mechanisms and processes involved in this complex phenomenon $[3,4]$.
Acid solutions are widely used in many applications, such as acid pickling, industrial acid cleaning, acid descaling, and oil well acidizing [5]. Due to the corrosivity of acid solutions, corrosion inhibitors are commonly added to their solutions in order to reduce their aggressive attack on the structure to be protected [5-10]. Inhibitors are generally used in this process to control the metal dissolution as well as acid consumption [5]. It has been reported [11-16] that organic compounds containing polar groups including nitrogen, sulfur, and oxygen and heterocyclic compounds with polar functional groups and conjugated double bonds have been known to be good corrosion inhibitors. The inhibiting action of these compounds is usually attributed to their interactions with the metal via their adsorption onto the surface. However, the adsorption of an inhibitor on a metal surface depends on 
the nature and the surface charge of the metal, the adsorption mode, its chemical structure, and the type of the electrolyte solution [17].

In the present work, we reported the effect of immersion time, namely, $10 \mathrm{~min}$ and $60 \mathrm{~min}$, on the electrochemical corrosion behavior of the HSLA steel in $2.0 \mathrm{M}$ sulfuric acid solutions. The effect of adding different concentrations of 3-amino-1,2,4-triazole (ATA) on the inhibition of this steel after the different exposure periods in the acid solution was also reported. The experimental part of this study was carried out using open-circuit potential (OCP), electrochemical impedance spectroscopy (EIS), and potentiodynamic polarization measurements. Characterization of the surface of the steel after its immersion in the acid solution alone and in the acid solution containing ATA molecules was performed using scanning electron microscopy (SEM) and energy dispersive X-ray (EDS) analyses.

\section{Experimental Details}

2.1. Chemicals and Electrochemical Cell. 3-Amino-1,2,4triazole (ATA, Sigma-Aldrich, $95 \%)$, sulfuric acid $\left(\mathrm{H}_{2} \mathrm{SO}_{4}\right.$, Merck, 96\%), absolute ethanol $\left(\mathrm{C}_{2} \mathrm{H}_{5} \mathrm{OH}\right.$, Merck, 99.9\%), and acetone $\left(\mathrm{C}_{3} \mathrm{H}_{6} \mathrm{O}\right.$, Merck, $\left.99.0 \%\right)$ were used as received. The HSLA steel electrode with a square shape and surface dimensions of $1 \times 1 \mathrm{~cm}$ was employed for the electrochemical tests. The chemical composition of the employed ultrahigh strength steel (in wt.\%) was as follows: $\mathrm{C}=0.0309, \mathrm{Si}=$ $0.177, \mathrm{Mn}=0.201, \mathrm{P}=0.007, \mathrm{Cr}=1.553, \mathrm{Mo}=$ $0.617, \mathrm{Ni}=3.208, \mathrm{Nb}=0.002, \mathrm{Al}=0.006, \mathrm{Cu}=$ $0.098, \mathrm{Co}=0.011, \mathrm{~B}=0.001, \mathrm{~V}=0.223, \mathrm{Sn}=$ 0.002 , and $\mathrm{N}=0.017$, and the balance $(\sim 93.566)$ was Fe. A conventional electrochemical cell accommodating only $200 \mathrm{~mL}$ with a three-electrode configuration was used. The three electrodes were the steel rod, platinum foil, and an $\mathrm{Ag} / \mathrm{AgCl}$ electrode (in $3.0 \mathrm{M} \mathrm{KCl}$ ) and were used as working, counter, and reference electrodes, respectively. The working electrode for electrochemical measurements was prepared by attaching an insulated copper wire to one face of the sample using an aluminum conducting tape and cold mounted in resin. The surface of the steel electrode to be exposed to the solution was first ground successively with metallographic emery paper of increasing fineness of up to 600 grits and further with $5,1,0.5$, and $0.3 \mu \mathrm{m}$ alumina slurries (Buehler). The electrode was then washed with doubly distilled water, degreased with acetone, washed using doubly distilled water again, and finally dried with tissue paper.

2.2. Electrochemical Measurements. An Autolab Potentiostat (PGSTAT20 computer controlled) operated by the General Purpose Electrochemical Software (GPES) version 4.9 was used to perform the electrochemical experiments. The opencircuit potential (OCP) curves obtained for the steel electrode in sulfuric acid in the absence and presence of ATA were done for $60 \mathrm{~min}$. The electrochemical impedance spectroscopy (EIS) tests were performed at corrosion potentials over a frequency range of $100 \mathrm{kHz}$ to $100 \mathrm{mHz}$, with an $\mathrm{AC}$ wave of $\pm 5 \mathrm{mV}$ peak-to-peak overlaid on a $\mathrm{DC}$ bias potential,

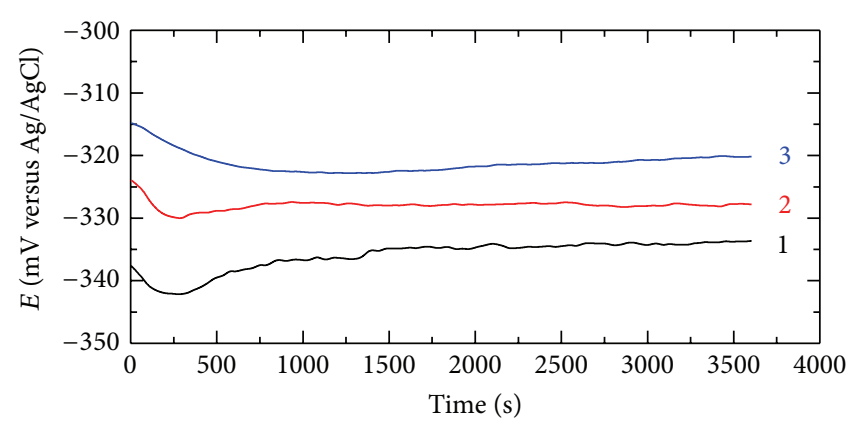

FIGURE 1: Change of the open-circuit potential versus time for the HSLA steel in $2.0 \mathrm{M} \mathrm{H}_{2} \mathrm{SO}_{4}$ solutions in the absence (1) and presence (2) of $1.0 \mathrm{mM}$ ATA and (3) $5.0 \mathrm{mM}$ ATA, respectively.

and the impedance data were collected using Powersine software at a rate of 10 points per decade change in frequency. The potentiodynamic polarization curves were obtained by scanning the potential in the forward direction from $-1.0 \mathrm{~V}$ to $-0.2 \mathrm{~V}$ versus $\mathrm{Ag} / \mathrm{AgCl}$ at a scan rate of $0.001 \mathrm{~V} / \mathrm{s}$. Each experiment was carried out using fresh steel surface and new portion of the sulfuric acid solution in the absence and the presence of the ATA molecules. All electrochemical experiments were carried out at room temperature.

2.3. SEM and EDS Investigations. The SEM images were obtained by using a JEOL model JSM-6610LV (Japanese made) scanning electron microscope with an energy dispersive $\mathrm{X}$-ray analyzer attached for acquiring the EDS analysis.

\section{Results and Discussion}

3.1. Open-Circuit Potential (OCP) Measurements. Figure 1 shows the OCP curves of the steel electrode in aerated stagnant $2.0 \mathrm{M} \mathrm{H}_{2} \mathrm{SO}_{4}$ solutions in the absence (1) and presence (2) of $1.0 \mathrm{mM}$ and (3) $5.0 \mathrm{mM}$ ATA, respectively. It is seen that the potential of the steel in the sulfuric acid solution without inhibitor (curve 1) increased towards the more negative values in the first $300 \mathrm{~s}$ of the steel immersion as a result of the dissolution of a preoxide film via the aggressiveness action of the acid solution. The potential then shifted again in the less negative direction through another 300 s before stabilizing a slight shift in the same direction with time till the end of the run.

The addition of $1.0 \mathrm{mM}$ ATA (curve 2) showed almost the same behavior but with a positive shift in the absolute potential, which indicates that ATA molecules at this concentration have an ability to decrease the severity of the acid solution. Increasing ATA concentration to $5.0 \mathrm{mM}$ (curve 3) presented more positive shifts in the absolute potential of the steel for the whole time of the experiment. The change of OCP with time measurements thus indicated that the presence of ATA molecules decreases the aggressiveness action of $\mathrm{H}_{2} \mathrm{SO}_{4}$ by shifting its potential in the less negative direction and this effect was found to increase with increase of the concentration of ATA. 


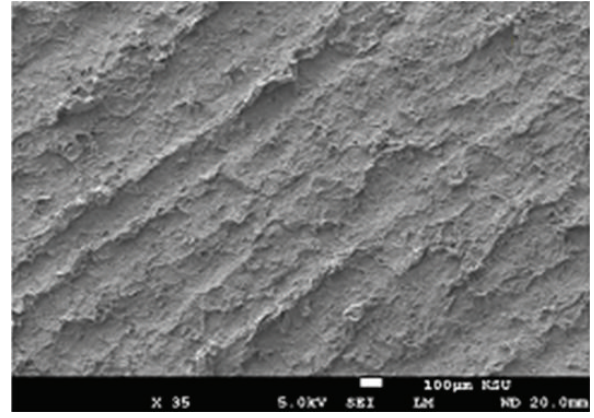

(a)

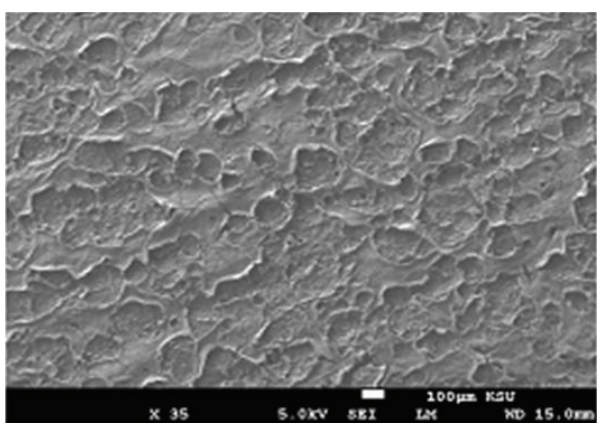

(b)

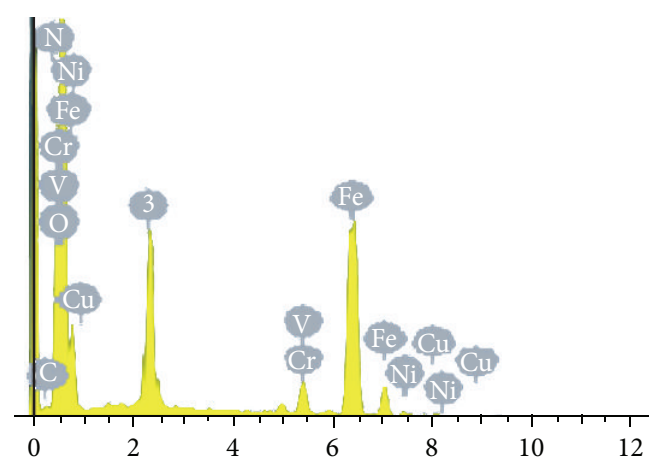

(c)

FIgURE 2: SEM micrographs obtained for the HSLA steel after $24 \mathrm{~h}$ immersion in $2.0 \mathrm{M} \mathrm{H}_{2} \mathrm{SO}_{4}$ solutions, (a) without ATA and (b) with $5.0 \mathrm{mM}$ ATA present, and (c) EDS profile analysis corresponding to the surface shown in Figure 2(b), respectively.

3.2. SEM and EDS Investigations. In order to investigate the effect of $\mathrm{H}_{2} \mathrm{SO}_{4}$ in the absence and presence of ATA molecules on the corrosion of the HSLA steel, SEM micrograph and EDS profile analysis were carried out. Figure 2 shows the SEM micrographs obtained for the HSLA steel after $24 \mathrm{~h}$ immersion in $2.0 \mathrm{M} \mathrm{H}_{2} \mathrm{SO}_{4}$ solutions, (a) without ATA and (b) with $5.0 \mathrm{mM}$ ATA present, and (c) EDS profile analysis corresponding to the surface shown in Figure 2(b), respectively. The SEM micrograph, shown in Figure 2(a), shows a total deterioration for the surface of steel, which was due to the aggressiveness attack of the sulfuric acid solution. The EDS profile analysis taken for the steel at this condition [7] indicated that its surface has the main alloying elements, in addition to the presence of carbon, sulfur, and oxygen. The presence of $\mathrm{C}, \mathrm{O}$, and $\mathrm{S}$ was due to the effect of sulfuric acid solutions as well as the exposure of the steel surface to air after removing it from the acid solution.

On the other hand, the SEM micrograph shown in Figure 2(b) proved that the surface of the steel is covered with a homogeneous layer of the adsorbed ATA molecules. This was confirmed by the EDS profile analysis shown in Figure 2(c), where the atomic percentages of the elements found on the steel surface were $5.44 \% \mathrm{C}, 0.93 \% \mathrm{~N}, 53.65 \% \mathrm{O}$, $7.34 \% \mathrm{~S}, 0.69 \% \mathrm{~V}, 2.49 \% \mathrm{Cr}, 0.77 \% \mathrm{Ni}, 0.12 \% \mathrm{Cu}$, and $28.58 \%$ Fe. The presence of nitrogen in the analysis confirms that the ATA molecules are included in the layer present on the surface. The presence of very high amount of Cr compared to that originally present in the steel, in addition to the very high percent of oxygen, indicates that the surface is also passivated through the formation of chromium oxide layer along with the adsorbed layer of the ATA molecules. Moreover, the presence of very low amounts of $\mathrm{Fe}$ and $\mathrm{Ni}$ reveals that the formed ATA layer is thick and is homogenously distributed on the surface. Another proof for the ability of the ATA molecules to inhibit the HSLA steel corrosion in the sulfuric acid test solution was the black color of the solution which did not have any ATA compound and was due to the severe dissolution of the steel, while the color of the acid solution containing $5.0 \mathrm{mM}$ ATA was clear and unchanged even after $24 \mathrm{~h}$ of the steel immersion. It has been reported $[9,18-$ 20] that the inhibition of metal corrosion by using similar compounds to ATA is achieved by the adsorption of their molecules onto the metal surface preventing it from being attacked by corrosive media.

3.3. Electrochemical Impedance Spectroscopy (EIS) Measurements. It has been reported [10, 20-22] that EIS is a powerful method in understanding the corrosion and corrosion inhibition for different metals and alloys in aggressive environments. In this work, we employed the EIS experiments to obtain the kinetic parameters for the steel/sulfuric acid solution interface after different exposure periods. In order to report the effect of immersion time on the corrosion of the HSLA steel in $2.0 \mathrm{M} \mathrm{H}_{2} \mathrm{SO}_{4}$ solution, the EIS measurements were conducted after (1) $10 \mathrm{~min}$ and (2) $60 \mathrm{~min}$ immersion and the Nyquist spectra were plotted, respectively, as shown in Figure 3. 


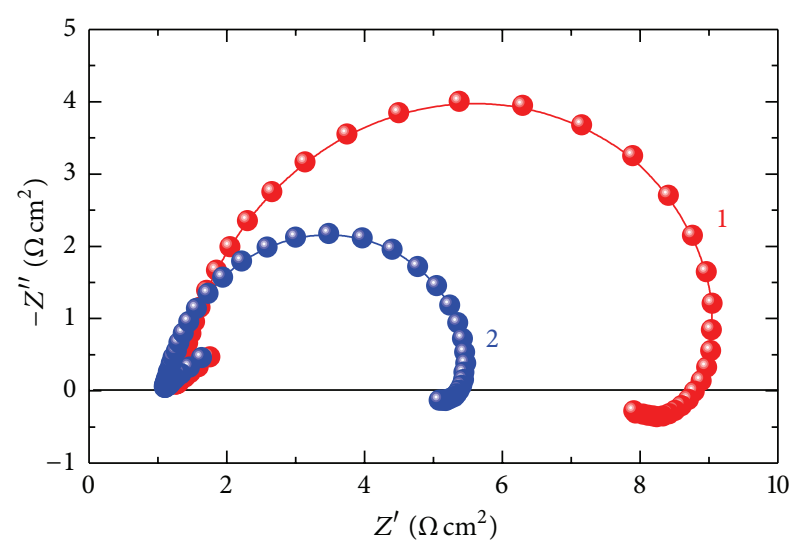

FIgURE 3: Nyquist plots for the HSLA steel after its immersion for (1) $10 \mathrm{~min}$ and (2) $60 \mathrm{~min}$ in the $2.0 \mathrm{M} \mathrm{H}_{2} \mathrm{SO}_{4}$ solutions, respectively.

It is clearly seen that the steel in the acid solution shows only one distorted semicircle whose diameter got smaller with the increase of immersion time from $10 \mathrm{~min}$ to $60 \mathrm{~min}$. This indicates that the increase of the time of immersion increases the dissolution of steel in sulfuric acid solution through decreasing its corrosion resistance. This was confirmed by fitting the EIS data to the best equivalent circuit model, which is shown in Figure 4. This equivalent circuit model was also used to fit the EIS data obtained from studying the corrosion and corrosion inhibition of maraging steel in different sulfuric acid solutions [7,9]. The parameters of the used circuit can be defined according to usual convention as follows: $R_{s}$ represents the solution resistance, $Q$ is the constant phase elements (CPEs), $R_{p 1}$ is the polarization resistance for the solution/steel interface and can be defined as the charge transfer resistance [23], $R_{p 2}$ is another polarization resistance for the corrosion product/steel interface, and $L$ is the inductance. The values of these parameters are listed in Table 1. It is also seen from Table 1 that the values of $R_{s}, R_{p 1}$, $R_{p 2}$, and $L$ decrease, while the value of $Q$ (CPEs) increases by the increase of immersion time from $10 \mathrm{~min}$ to $60 \mathrm{~min}$ for the HSLA steel in $2.0 \mathrm{M} \mathrm{H}_{2} \mathrm{SO}_{4}$ solutions. This is due to the corrosiveness action of the sulfuric acid solution that continuously attacks the surface of the steel and lowers its probability to develop oxide layers or corrosion products and that effect increases with increasing time of contact between the acid and the steel.

The EIS measurements were also employed to report the effect of ATA molecules on the inhibition of the HSLA steel in $2.0 \mathrm{M} \mathrm{H}_{2} \mathrm{SO}_{4}$ solutions. Figure 5 shows the Nyquist plots obtained for the steel after $10 \mathrm{~min}$ immersion in the acid solution that contains (1) 0.0 , (2) 1.0 , and (3) $5.0 \mathrm{mM}$ ATA, respectively. Similar plots were also obtained for the HSLA steel after its immersion in the acid solution in the absence and presence of ATA for $60 \mathrm{~min}$ and the curves are shown in Figure 6. The equivalent circuit shown in Figure 4 was also used to represent the best fitting for the data presented in Figures 5 and 6 . The EIS parameters obtained out of the fitted data as well as the values of the percentage of the inhibition

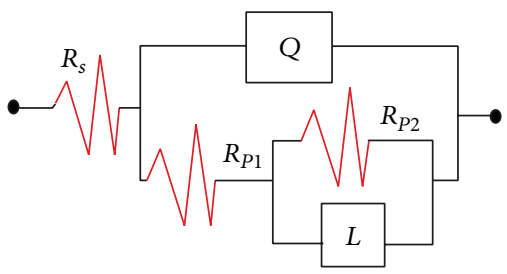

FIGURE 4: The equivalent circuit used to fit the experimental EIS data obtained for the HSLA steel after its immersion for different periods of time in $2.0 \mathrm{M}$ sulfuric acid solution.

efficiency (IE\%) are listed in Table 1. The values of IE\% were calculated according to the following equation [18]:

$$
\mathrm{IE} \%=\frac{R_{P}^{\mathrm{in}}-R_{P}^{\mathrm{O}}}{R_{P}^{\mathrm{in}}},
$$

where $R_{P}^{\text {in }}$ and $R_{P}^{\mathrm{O}}$ are polarization resistance of the HSLA steel in the sulfuric acid solution in the presence and absence of ATA molecules, respectively.

It is clearly seen from Figure 5 that the addition of $1.0 \mathrm{mM}$ ATA within the sulfuric acid solution increased the diameter of the semicircle. Increasing the concentration of ATA to $5.0 \mathrm{mM}$ further increased the diameter of the semicircle obtained for the steel. This indicates that the presence of ATA and the increase of its concentration decrease the corrosion of the HSLA steel after $10 \mathrm{~min}$ immersion in $2.0 \mathrm{M}$ $\mathrm{H}_{2} \mathrm{SO}_{4}$ solutions. It has been reported $[18,20,24]$ that ATA molecules inhibit the corrosion via their adsorption onto the surface of metals (such as iron [20] and copper [18, 24]) and the ability of ATA as a corrosion inhibitor increases with the increase of its concentration. This agrees with the current results as indicated by the parameters recorded in Table 1, where the values of $R_{s}, R_{p 1}, R_{p 2}$, and $L$ as well as IE\% increased with the increase of ATA concentration.

It is obvious from Figure 6 for the steel after $60 \mathrm{~min}$ in the acid solution without and with ATA present that the presence of $1.0 \mathrm{mM}$ ATA decreased the aggressiveness action of the sulfuric acid solution by increasing its corrosion resistance. This was revealed by increasing the diameter of the semicircle obtained for the steel in the presence of $1.0 \mathrm{mM}$ ATA compared to its diameter in the blank solution. Further increasing the ATA concentration to $5.0 \mathrm{mM}$ produced further increase in the diameter of the semicircle after $60 \mathrm{~min}$. Table 1 also confirmed that the presence of ATA and the increase of its concentration increased the values of $R_{s}, R_{p 1}$, $R_{p 2}$, and $L$. The increase of $R_{s}, R_{p 1}$, and $R_{p 2}$ in the presence of ATA and with the increase of its content indicates that ATA molecules have the ability to increase the solution and corrosion resistance of the HSLA steel surface and that effect increases with increasing ATA concentration in the acid solution. The values of CPEs with their $n$ values close to unity represent double layer capacitors decreased in the presence of ATA and with the increase of its content, which was expected to cover up the charged surfaces [23]. Moreover, the values of IE\% were found to increase not only with increasing concentration of ATA from $1.0 \mathrm{mM}$ to $5.0 \mathrm{mM}$ but also with increasing the immersion time as can be seen from Table 1 . 
TABLE 1: Parameters obtained by fitting the EIS data with the equivalent circuit shown in Figure 4 for the HSLA steel in $2.0 \mathrm{M} \mathrm{H}_{2} \mathrm{SO}_{4}$ solutions.

\begin{tabular}{|c|c|c|c|c|c|c|c|}
\hline \multirow[b]{2}{*}{ Solution } & \multicolumn{7}{|c|}{ Parameter } \\
\hline & $R_{s} / \Omega \mathrm{cm}^{2}$ & $Y_{\mathrm{Q}} / \mathrm{F} \mathrm{cm}^{-2}$ & $n$ & $R_{P 1} / \Omega \mathrm{cm}^{2}$ & $R_{P 2} / \Omega \mathrm{cm}^{2}$ & $L / H$ & IE \% \\
\hline $2.0 \mathrm{M} \mathrm{H}_{2} \mathrm{SO}_{4}(10 \mathrm{~min})$ & 1.357 & 0.00145 & 0.80 & 6.766 & 3.204 & 15.347 & - \\
\hline$+1.0 \mathrm{mM}$ ATA $(10 \mathrm{~min})$ & 1.491 & 0.00122 & 0.88 & 10.747 & 3.301 & 15.611 & 37.1 \\
\hline$+5.0 \mathrm{mM}$ ATA $(10 \mathrm{~min})$ & 1.860 & 0.00103 & 0.92 & 14.000 & 3.977 & 16.92 & 51.7 \\
\hline $2.0 \mathrm{M} \mathrm{H}_{2} \mathrm{SO}_{4}(60 \mathrm{~min})$ & 1.280 & 0.00257 & 0.84 & 5.354 & 2.279 & 13.73 & - \\
\hline$+1.0 \mathrm{mM}$ ATA $(60 \mathrm{~min})$ & 1.434 & 0.00187 & 0.87 & 8.993 & 3.267 & 15.716 & 40.5 \\
\hline$+5.0 \mathrm{mM}$ ATA $(60 \mathrm{~min})$ & 1.657 & 0.00179 & 0.92 & 12.07 & 3.355 & 16.602 & 55.64 \\
\hline
\end{tabular}

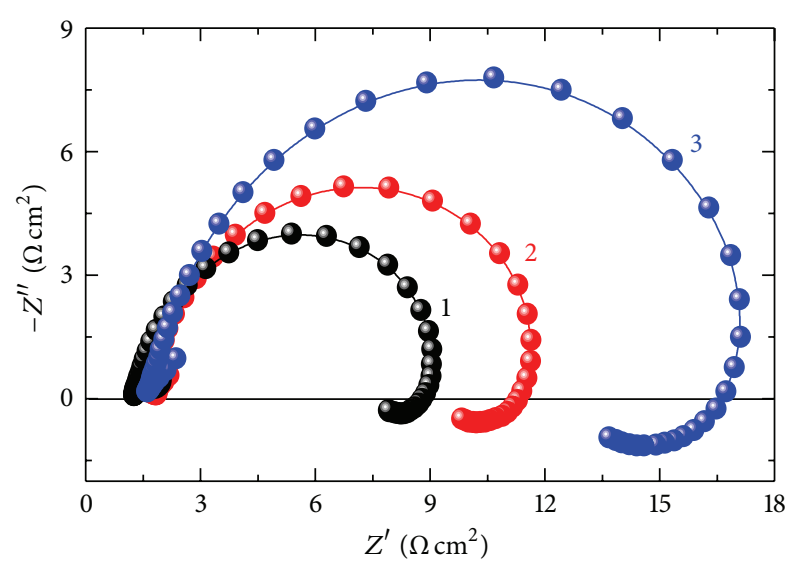

FIGURE 5: Nyquist plots for the HSLA steel after its immersion for $10 \mathrm{~min}$ in $2.0 \mathrm{M} \mathrm{H}_{2} \mathrm{SO}_{4}$ solutions in (1) the absence and the presence of (2) $1 \mathrm{mM}$ ATA and (3) $5 \mathrm{mM}$ ATA, respectively.

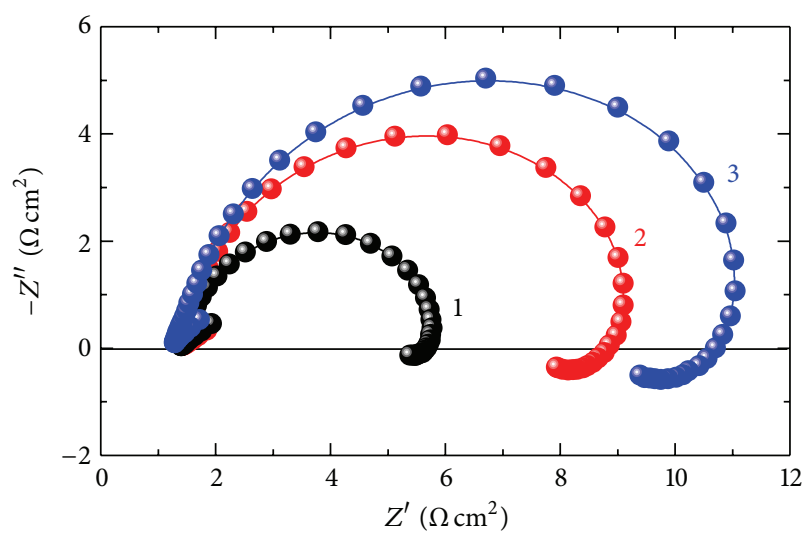

FIGURE 6: Nyquist plots for the HSLA steel after its immersion for $60 \mathrm{~min}$ in $2.0 \mathrm{M} \mathrm{H}_{2} \mathrm{SO}_{4}$ solutions in (1) the absence and the presence of (2) $1 \mathrm{mM}$ ATA and (3) $5 \mathrm{mM}$ ATA, respectively.

The outcome of the EIS experiments proves that ATA can be employed to mitigate the corrosion of the HSLA steel in $2.0 \mathrm{M}$ $\mathrm{H}_{2} \mathrm{SO}_{4}$ solutions and its ability as a good corrosion inhibitor increases with the increase of its concentration as well as the increase of the time of immersion before measurement.
3.4. Potentiodynamic Polarization Measurements. The effect of increasing the immersion time on the dissolution of the HSLA steel in $2.0 \mathrm{M} \mathrm{H}_{2} \mathrm{SO}_{4}$ solutions was investigated using potentiodynamic polarization measurements. The potentiodynamic polarization curves obtained for HSLA steel after its immersion in $2.0 \mathrm{M} \mathrm{H}_{2} \mathrm{SO}_{4}$ solutions for (1) $10 \mathrm{~min}$ and (2) $60 \mathrm{~min}$ are shown in Figure 7. The corrosion potential $\left(E_{\mathrm{Corr}}\right)$, corrosion current density $\left(j_{\text {Corr }}\right)$, cathodic $(\beta c)$ and anodic $(\beta a)$ Tafel slopes, polarization resistance $\left(R_{p}\right)$, and corrosion rate $\left(R_{\text {Corr }}\right)$ that were obtained from polarization curves are listed in Table 2. The values of these parameters were obtained as previously reported [17-21]. It is clearly seen from Figure 7 and Table 2 that the increase of immersion time increases the values of $j_{\text {Corr }}$, cathodic and anodic currents, and $R_{\text {Corr }}$, while it decreases the values of $R_{p}$. This was due to the continuous dissolution of the HSLA steel under the harsh attack of the concentrated solution of the sulfuric acid, which does not allow the surface of steel to form protective layers and/or corrosion products. At this condition, the cathodic reaction for the steel in the sulfuric acid solution has been reported to be the hydrogen evolution reaction as follows $[7,9,25]$ :

$$
2 \mathrm{H}^{+}+2 \mathrm{e}^{-}=\mathrm{H}_{2}
$$

On the other hand, the anodic reaction of the HSLA steel is the dissolution of its iron according to the following equation $[7,9]$ :

$$
\mathrm{Fe}=\mathrm{Fe}^{2+}+2 \mathrm{e}^{-}
$$

The resulting ferrous cations $\left(\mathrm{Fe}^{2+}\right)$ are not stable and oxidize to ferric cations $\left(\mathrm{Fe}^{3+}\right)$ as follows:

$$
\mathrm{Fe}^{2+}=\mathrm{Fe}^{3+}+\mathrm{e}^{-}
$$

The severity of these reactions increases with increase of the immersion time, which could lead to the increased dissolution of steel and also explain the increased currents and corrosion rate with increasing the time of immersion.

In order to evaluate the effect of ATA as a corrosion inhibitor after the different stated exposure intervals, the potentiodynamic polarization measurements were also carried out. Figure 8 shows the potentiodynamic polarization curves obtained for the HSLA steel after its immersion in 
TABLE 2: Corrosion parameters obtained from the potentiodynamic polarization measurements for the HSLA steel electrode that was immersed for different periods of time in $2.0 \mathrm{M} \mathrm{H}_{2} \mathrm{SO}_{4}$ solutions with and without ATA molecules.

\begin{tabular}{|c|c|c|c|c|c|c|c|}
\hline \multirow{2}{*}{ Medium } & \multicolumn{7}{|c|}{ Parameter } \\
\hline & $\begin{array}{c}\beta_{c} \\
\mathrm{mV} \mathrm{dec}^{-1}\end{array}$ & $\begin{array}{c}E_{\mathrm{Corr}} \\
\mathrm{mV}\end{array}$ & $\begin{array}{c}j_{\text {Corr }} \\
\mu \mathrm{A} \mathrm{cm}^{-2}\end{array}$ & $\begin{array}{c}\beta_{a} \\
\mathrm{mV} \mathrm{dec}^{-1}\end{array}$ & $\begin{array}{c}R_{p} \\
\Omega \mathrm{cm}^{2}\end{array}$ & $\begin{array}{c}R_{\text {Corr }} \\
\mathrm{mm} \mathrm{y}^{-1}\end{array}$ & $\begin{array}{l}\text { IE } \\
\%\end{array}$ \\
\hline $2.0 \mathrm{M} \mathrm{H}_{2} \mathrm{SO}_{4}(10 \mathrm{~min})$ & -90 & -342 & 2750 & 65 & 3.73 & 27.57 & - \\
\hline$+1.0 \mathrm{mM}$ ATA (10 min) & -85 & -335 & 1800 & 70 & 9.62 & 18.04 & 34.54 \\
\hline$+5.0 \mathrm{mM}$ ATA $(10 \mathrm{~min})$ & -82 & -330 & 1300 & 75 & 19.4 & 13.03 & 52.73 \\
\hline $2.0 \mathrm{M} \mathrm{H}_{2} \mathrm{SO}_{4}(60 \mathrm{~min})$ & -85 & -325 & 4600 & 60 & 1.94 & 46.11 & - \\
\hline+1.0 mM ATA (60 min) & -78 & -330 & 2400 & 63 & 5.93 & 24.06 & 47.83 \\
\hline +5.0 mM ATA (60 min) & -72 & -325 & 1500 & 67 & 18.1 & 15.04 & 67.39 \\
\hline
\end{tabular}

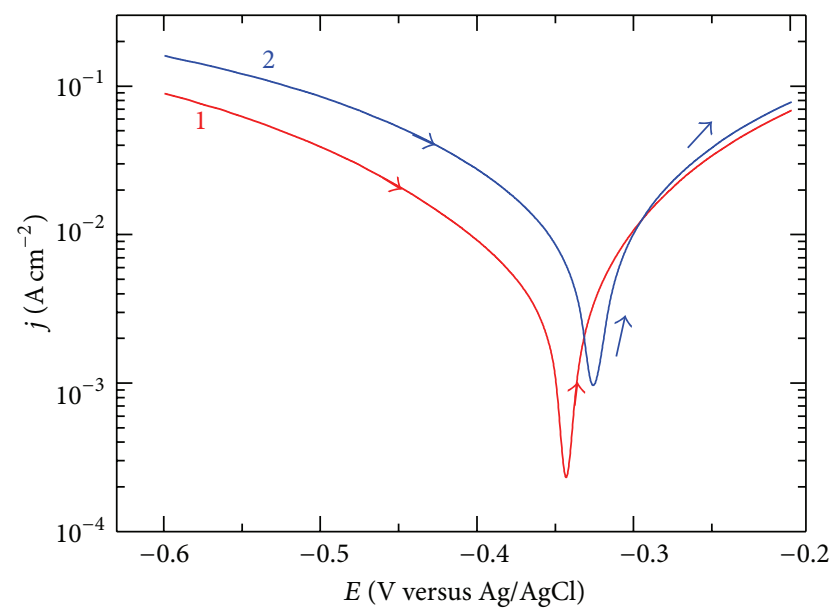

FIGURE 7: Potentiodynamic polarization curves obtained for the HSLA steel after its immersion for (1) $10 \mathrm{~min}$ and (2) $60 \mathrm{~min}$ in $2.0 \mathrm{M}$ $\mathrm{H}_{2} \mathrm{SO}_{4}$ solutions.

2.0 $\mathrm{M} \mathrm{H}_{2} \mathrm{SO}_{4}$ solutions for $10 \mathrm{~min}$ in (1) the absence and the presence of (2) $1.0 \mathrm{mM}$ and (3) $5.0 \mathrm{mM}$ ATA, respectively. In order to study the effect of immersion time on the efficiency of ATA molecules, the polarization measurements were performed after $60 \mathrm{~min}$ and the curves are shown in Figure 9. The values of the parameters obtained from Figures 8 and 9 as well as the calculated values of IE\% are also listed in Table 2. The values of IE\% were obtained from the polarization data according to the following equation $[9,17$, 18]:

$$
\mathrm{IE} \%=\frac{j_{\text {Corr }}-j_{\text {Corr }}^{\mathrm{o}}}{j_{\text {Corr }}} \times 100,
$$

where $j_{\text {Corr }}$ and $j_{\text {Corr }}^{\text {o }}$ are the corrosion current densities in the absence and presence of ATA molecules, respectively.

The addition of $1.0 \mathrm{mM}$ ATA within the acid solution after all immersion periods of time remarkably decreased the anodic, cathodic, and corrosion currents. The data listed in Table 2 also indicated that the values of $j_{\text {Corr }}$ and $R_{\text {Corr }}$ decreased, while the value of $R_{p}$ increased in the presence of $1.0 \mathrm{mM}$ ATA compared to those recorded in its absence. This was perhaps due to the ability of ATA molecules to be adsorbed onto the steel surface, where the adsorption of

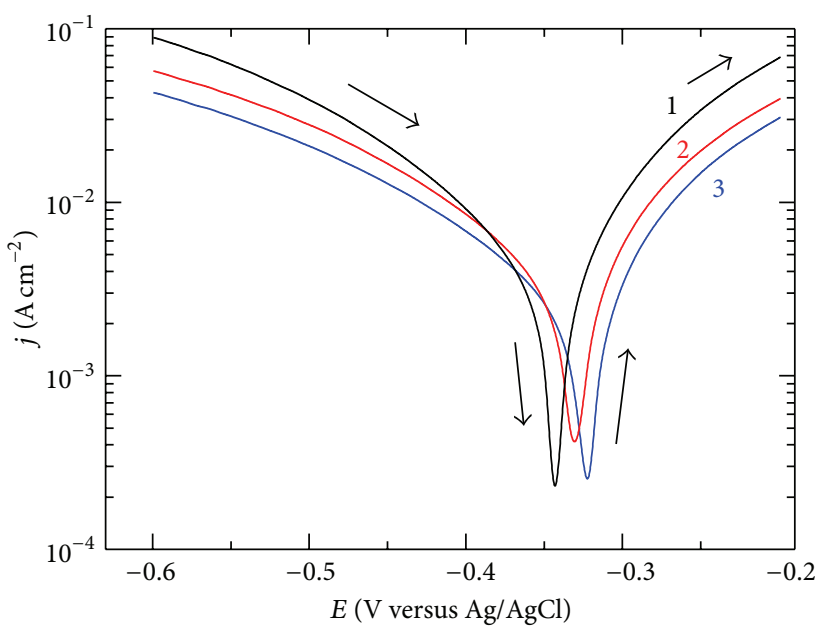

FIGURE 8: Potentiodynamic polarization curves obtained for the HSLA steel after its immersion for $10 \mathrm{~min}$ in $2.0 \mathrm{M} \mathrm{H}_{2} \mathrm{SO}_{4}$ in the absence (1) and the presence of (2) $1.0 \mathrm{mM}$ ATA and (3) $5.0 \mathrm{mM}$ ATA, respectively.

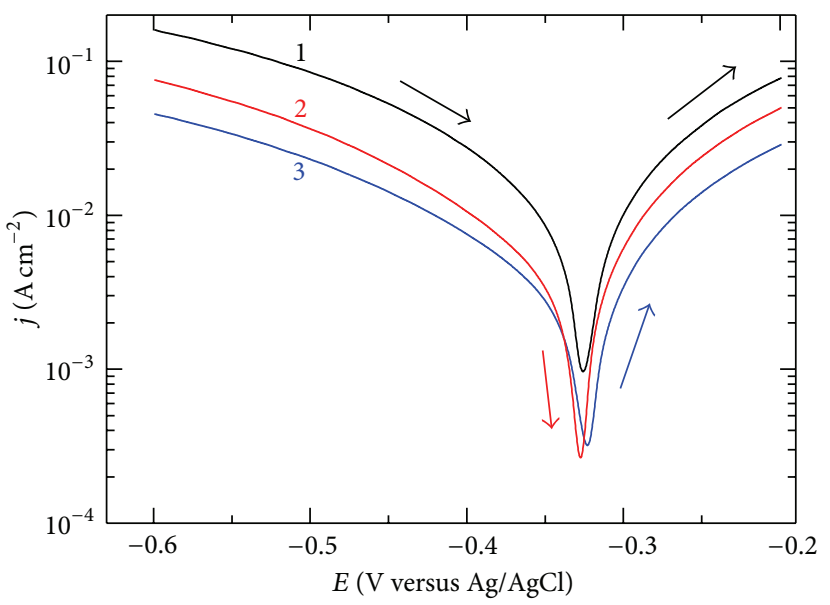

FIGURE 9: Potentiodynamic polarization curves obtained for the HSLA steel after its immersion for $60 \mathrm{~min}$ in $2.0 \mathrm{M} \mathrm{H}_{2} \mathrm{SO}_{4}$ in the absence (1) and the presence (2) of $1.0 \mathrm{mM}$ ATA and (3) 5.0 mM ATA, respectively. 
ATA molecules onto the steel results in the formation of a protective layer that in turn not only isolates the surface but also blocks its active sites and thus precludes the corrosion of the steel in the corrosive $2.0 \mathrm{M}$ sulfuric acid solution. It is also seen that the increase of ATA concentration to $5.0 \mathrm{mM}$ greatly decreased the values of $j_{\text {Corr }}$ and $R_{\text {Corr }}$ and pronouncedly increased the value of $R_{p}$, particularly when the immersion time was increasing. This means that the increase of ATA concentration increases the adsorption probability of its molecules, which increases the efficiency of the formed layers in protecting the steel surface from being corroded easily. This was also indicated by the increase of the values of IE\% with the increase of ATA concentration as listed in Table 2.

Although the corrosion of the HSLA steel increased with increasing the immersion time in $2.0 \mathrm{M} \mathrm{H}_{2} \mathrm{SO}_{4}$ solutions in the absence of ATA molecules, the corrosion of the steel was found to significantly decrease with the increase of immersion time in the presence of ATA and with the increase of its concentration. The increased corrosion of the HSLA steel in the absence of ATA was due to the rapid and harsh attack of the acid molecules toward the steel that makes its surface fresh, active, and dissolvable. On the other hand, the presence of ATA and the increase of its concentration strongly decrease the corrosion of the steel with increasing the immersion time as a result of decreasing the values of anodic and cathodic currents, $j_{\text {Corr }}$ and $R_{\text {Corr }}$, and increasing the values of $R_{p}$. The decrease of the anodic and cathodic currents in the presence of ATA and with the increase of its concentration confirm that ATA is a mixed type corrosion inhibitor. The decrease of steel corrosion with time in the presence of ATA is due to the thickening of the adsorbed ATA layers onto the steel surface, which makes it more protected and precludes its dissolution. This was also confirmed by the large increase in IE\% values with the increase of immersion time (see Table 2). The results obtained from the potentiodynamic polarization measurements therefore confirm those ones obtained by the EIS experiments and that the corrosion of HSLA steel increases with increasing the immersion time in the sulfuric acid solutions. It is also agreed that the addition of $1.0 \mathrm{mM}$ ATA decreases the corrosion of steel and that effect increases with increasing both the concentration of ATA to $5.0 \mathrm{mM}$ and the time of immersion from $10 \mathrm{~min}$ to $60 \mathrm{~min}$.

\section{Conclusions}

The corrosion and corrosion control of HSLA steel in $2.0 \mathrm{M}$ $\mathrm{H}_{2} \mathrm{SO}_{4}$ solutions using ATA as a corrosion inhibitor after different exposure intervals were reported. Electrochemical measurements indicated that the increase of immersion time from $10 \mathrm{~min}$ to $60 \mathrm{~min}$ increased the corrosion of the HSLA steel in the sulfuric acid solutions. On the other hand, the presence of ATA and the increase of its concentration were found to provide good corrosion inhibition and that effect increased with increasing the immersion time. This was confirmed by the increase of the polarization and solution resistance as well as the decrease of the anodic, cathodic, and corrosion currents, which in turn decreased the corrosion rate of HSLA in the acid medium. Moreover, the calculated value of the inhibition efficiency, IE\%, was found to remarkably increase with increasing both ATA concentration and immersion time. Results collectively were in good agreement with each other showing clearly that the corrosion of HSLA steel increases with time and also ATA is a good mixed corrosion inhibitor due to the adsorption of its molecules onto the steel surface.

\section{Conflict of Interests}

The authors declare that there is no conflict of interests regarding the publication of this paper.

\section{Acknowledgment}

The authors would like to extend their sincere appreciation to the Deanship of Scientific Research at King Saud University for its funding of this research through the Research Group Project no. RGP-VPP-160.

\section{References}

[1] S. L. Chawla and R. K. Gupta, "Materials Selection for Corrosion Control," ASM International, 1993, http://www .asminternational.org/.

[2] I. B. Timokhina, P. D. Hodgson, S. P. Ringer, R. K. Zheng, and E. V. Pereloma, "Precipitate characterisation of an advanced highstrength low-alloy (HSLA) steel using atom probe tomography," Scripta Materialia, vol. 56, no. 7, pp. 601-604, 2007.

[3] C. A. Melendres, N. Camillone III, and T. Tipton, "Laser raman spectroelectrochemical studies of anodic corrosion and film formation on iron in phosphate solutions," Electrochimica Acta, vol. 34, no. 2, pp. 281-286, 1989.

[4] J. L. Yao, B. Ren, Z. F. Huang, P. G. Cao, R. A. Gu, and Z.-Q. Tian, "Extending surface Raman spectroscopy to transition metals for practical applications IV. A study on corrosion inhibition of benzotriazole on bare Fe electrodes," Electrochimica Acta, vol. 48, no. 9, pp. 1263-1271, 2003.

[5] F. Bentiss, M. Traisnel, L. Gengembre, and M. Lagrenée, "Inhibition of acidic corrosion of mild steel by 3,5-diphenyl- $4 \mathrm{H}$ 1,2,4-triazole," Applied Surface Science, vol. 161, no. 1, pp. 194202, 2000.

[6] F. B. Growcock and V. R. Lopp, "The inhibition of steel corrosion in hydrochloric acid with 3-phenyl-2-propyn-1-ol," Corrosion Science, vol. 28, no. 4, pp. 397-410, 1988.

[7] E.-S. M. Sherif and A. H. Seikh, "Effects of immersion time and 5-Phenyl- $1 \mathrm{H}$-tetrazole on the corrosion and corrosion mitigation of cobalt free maraging steel in $0.5 \mathrm{M}$ sulfuric acid pickling solutions," Journal of Chemistry, vol. 2013, Article ID 497823, 7 pages, 2013.

[8] S. L. Granese, "Study of the inhibitory action of nitrogencontaining compounds," Corrosion, vol. 44, no. 6, pp. 322-327, 1988.

[9] E.-S. M. Sherif, "Corrosion inhibition in 2.0 M sulfuric acid solutions of high strength maraging steel by aminophenyl tetrazole as a corrosion inhibitor," Applied Surface Science, vol. 292, pp. 190-196, 2014.

[10] M. Lagrenée, B. Mernari, M. Bouanis, M. Traisnel, and F. Bentiss, "Study of the mechanism and inhibiting efficiency of 3,5-bis(4-methylthiophenyl)-4H-1,2,4-triazole on mild steel 
corrosion in acidic media," Corrosion Science, vol. 44, no. 3, pp. 573-588, 2002.

[11] O. L. Riggs Jr., Corrosion Inhibitors, 2nd edition, edited by C. C. Nathan, National Association of Corrosion Engineers, Houston, Tex, USA, 1973.

[12] M. Bartos and N. Hackerman, "A Study of inhibition action of propargyl alcohol during anodic dissolution of iron in hydrochloric acid," Journal of the Electrochemical Society, vol. 139, no. 12, pp. 3428-3433, 1992.

[13] A. M. S. Abdennabi, A. I. Abdulhadi, S. T. Abu-Orabi, and H. Saricimen, "The inhibition action of 1(benzyl)1-H-4,5dibenzoyl-1,2,3-triazole on mild steel in hydrochloric acid media," Corrosion Science, vol. 38, no. 10, pp. 1791-1800, 1996.

[14] A. Chetouani, B. Hammouti, A. Aouniti, N. Benchat, and T. Benhadda, "New synthesised pyridazine derivatives as effective inhibitors for the corrosion of pure iron in $\mathrm{HCl}$ medium," Progress in Organic Coatings, vol. 45, no. 4, pp. 373-378, 2002.

[15] M. Elayyachy, B. Hammouti, A. El Idrissi, and A. Aouniti, "Adsorption and corrosion inhibition behavior of C38 steel by one derivative of quinoxaline in $1 \mathrm{M} \mathrm{HCl}$," Portugaliae Electrochimica Acta, vol. 29, no. 1, pp. 57-68, 2011.

[16] A. Zarrouk, I. Warad, B. Hammouti, A. Dafali, S. S. Al-Deyab, and N. Benchat, "The effect of temperature on the corrosion of $\mathrm{Cu} / \mathrm{HNO}_{3}$ in the Presence of organic inhibitor: part-2," International Journal of Electrochemical Science, vol. 5, no. 10, pp. 1516-1526, 2010.

[17] E.-S. M. Sherif, "Corrosion mitigation of copper in acidic chloride pickling solutions by 2-amino-5-ethyl-1,3,4-thiadiazole," Journal of Materials Engineering and Performance, vol. 19, no. 6, pp. 873-879, 2010.

[18] E.-S. M. Sherif, "Comparative study on the inhibition of iron corrosion in aerated stagnant $3.5 \mathrm{wt} \%$ sodium chloride solutions by 5-phenyl-1H-tetrazole and 3-amino-1,2,4-triazole," Industrial and Engineering Chemistry Research, vol. 52, no. 41, pp. 14507-14513, 2013.

[19] E.-S. M. Sherif, A. M. El Shamy, M. M. Ramla, and A. O. H. El Nazhawy, "5-(Phenyl)-4H-1,2,4-triazole-3-thiol as a corrosion inhibitor for copper in $3.5 \% \mathrm{NaCl}$ solutions," Materials Chemistry and Physics, vol. 102, no. 2-3, pp. 231-239, 2007.

[20] E.-S. M. Sherif and A. H. Ahmed, "Synthesizing new hydrazone derivatives and studying their effects on the inhibition of copper corrosion in sodium chloride solutions," Synthesis and Reactivity in Inorganic, Metal-Organic and Nano-Metal Chemistry, vol. 40, no. 6, pp. 365-372, 2010.

[21] E. M. Sherif and S.-M. Park, "Inhibition of copper corrosion in acidic pickling solutions by N-phenyl-1,4-phenylenediamine," Electrochimica Acta, vol. 51, no. 22, pp. 4665-4673, 2006.

[22] S. N. Banerjee and S. Misra, "1,10,-phenanthroline as corrosion inhibitor for mild steel in sulfuric acid solution," Corrosion, vol. 45 , no. 9, pp. 780-783, 1989.

[23] H. Ma, S. Chen, L. Niu, S. Zhao, S. Li, and D. Li, "Inhibition of copper corrosion by several Schiff bases in aerated halide solutions," Journal of Applied Electrochemistry, vol. 32, no. 1, pp. 65-72, 2002.

[24] E.-S. M. Sherif, R. M. Erasmus, and J. D. Comins, "Corrosion of copper in aerated synthetic sea water solutions and its inhibition by 3-amino-1,2,4-triazole," Journal of Colloid and Interface Science, vol. 309, no. 2, pp. 470-477, 2007.

[25] E. S. M. Sherif, "Corrosion behavior of duplex stainless steel alloy cathodically modified with minor ruthenium additions in concentrated sulfuric acid solutions," International Journal of Electrochemical Science, vol. 6, no. 7, pp. 2284-2298, 2011. 

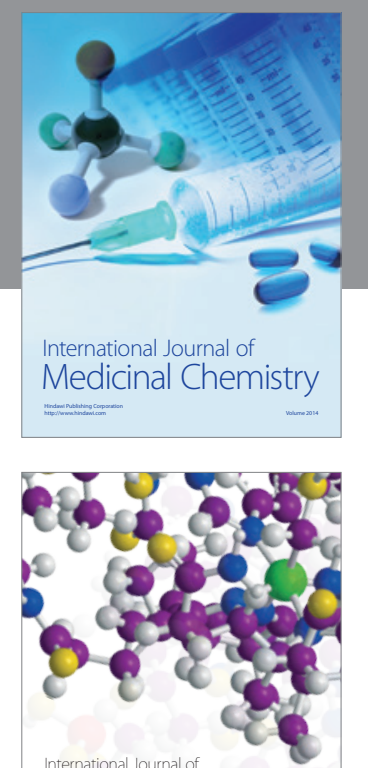

\section{Carbohydrate} Chemistry

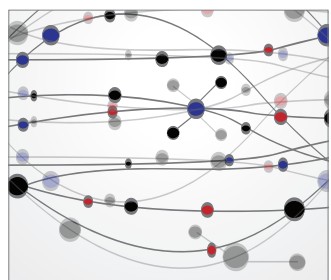

The Scientific World Journal
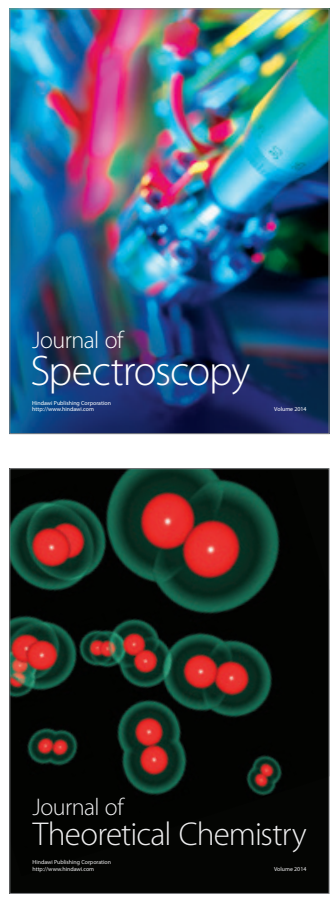
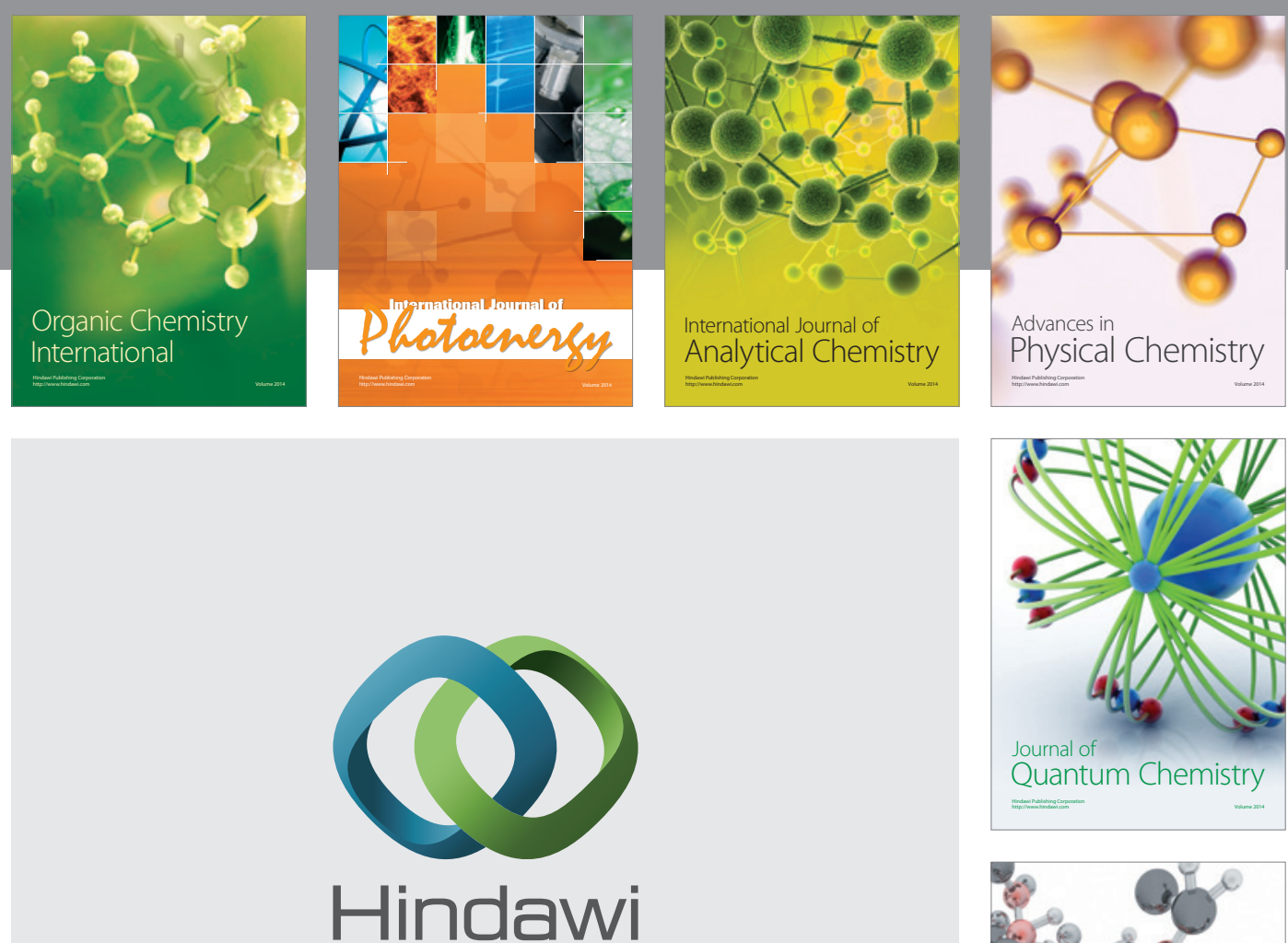

Submit your manuscripts at

http://www.hindawi.com

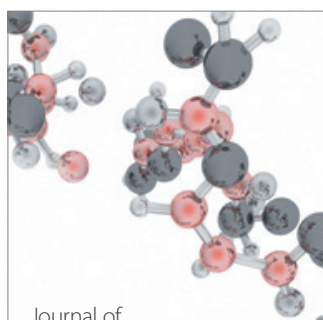

Analytical Methods

in Chemistry

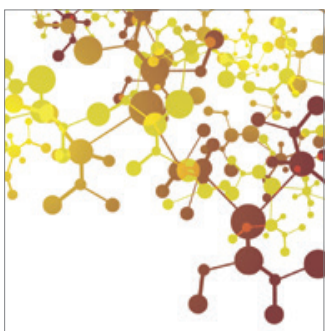

Journal of

Applied Chemistry

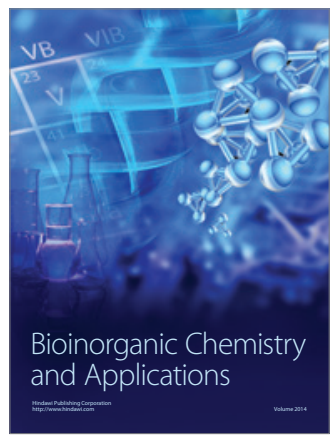

Inorganic Chemistry
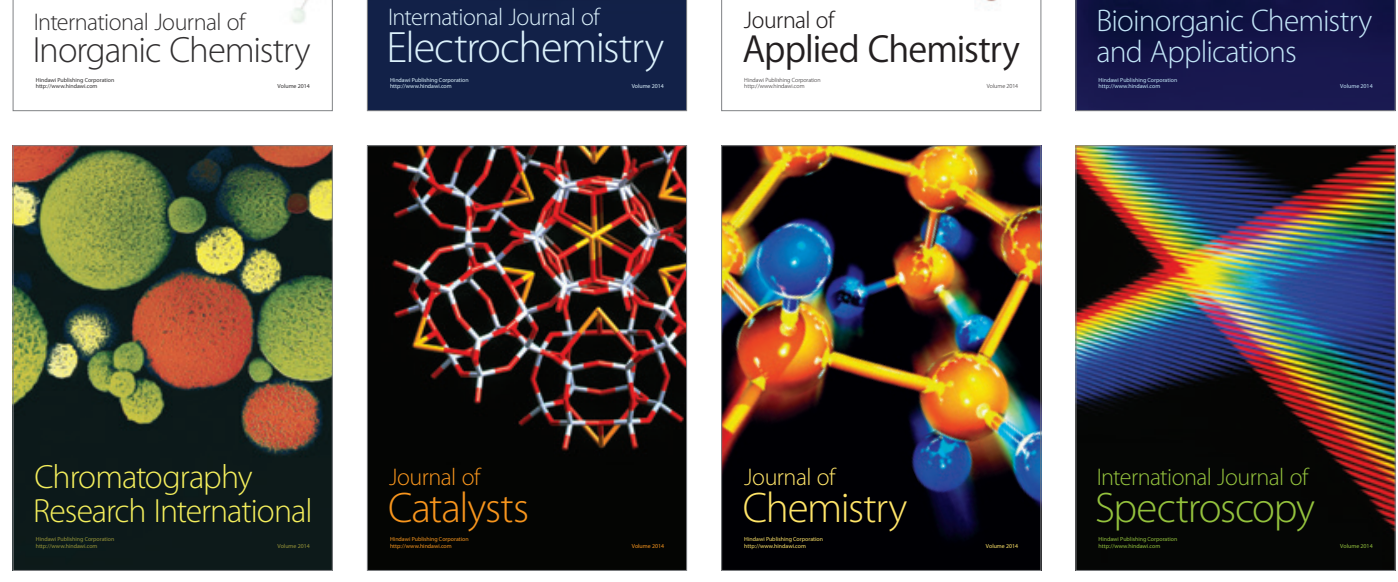